\title{
TUNING OF PID CONTROLLER OF INVERTED PENDULUM USING GENETIC ALGORITHM
}

\author{
P. Kumar ${ }^{1}$, O.N. Mehrotra ${ }^{2}$, J. Mahto ${ }^{3}$
}

\begin{abstract}
The paper presents two different ways of mathematical modeling of Inverted Pendulum. A Proportional-Integral-Derative (PID) controller is designed for its stabilization. Some reference stable system is selected after designing of PID controller to optimize different types of error using Genetic Algorithms. The proposed system extends classical inverted pendulum by incorporating two moving masses. A tuning mechanism is implemented by genetic algorithm for optimizing different gains of controller parameter. Also, different performance indices are calculated in MATLAB environment. This paper exhibits to demonstrate the capability of genetic algorithm to solve complex and constraint optimization problems and as a general purpose optimization tool to solve control system design problems.
\end{abstract}

Keyword-Inverted pendulum,Mathematical modelling,swing up control ,PID controller,Tuning, Genetic

Algorithm,Performance Indeces,Error minimization.

$* * * * *$

\section{INTRODUCTION}

The inverted pendulum may be viewed as a classical problem in dynamics and control theory[1,9] and is widely used as a benchmark[16] for testing control algorithms(PID controllers, Linear Quadratic Regulator (LQR), neural networks, fuzzy logic control, genetic algorithms, etc)[7,8].The inverted pendulum is unstable[11] in the sense that it may fall any time in any direction unless a suitable control force is applied. The control objective of the inverted pendulum is to swing up[4] the pendulum hinged on the moving cart by a linear motor[12] from stable position (vertically down state) to the zero state(vertically upward state) and to keep the pendulum in vertically upward state in spite of the disturbance[5,13].

In the field of engineering and technology the importance of benchmark [14,7] needs no explanation. They make it easy to check whether a particular algorithm [6] yields the requisite results.

Several work has been reported on the inverted pendulum for its stabilization. Attempts have been made in the past to control it using classical control [3]. In this paper, the controller is proposed to be tuned using Genetic Algorithm(GA)[15] technique.. Genetic Algorithm[2,10] have been shown to be capable of locating high performance areas in complex domains without experiencing difficulties, even associated with high dimensionality or false optima as many occurring with some other optimization method.

\section{MECHANICAL CONSTRUCTION}

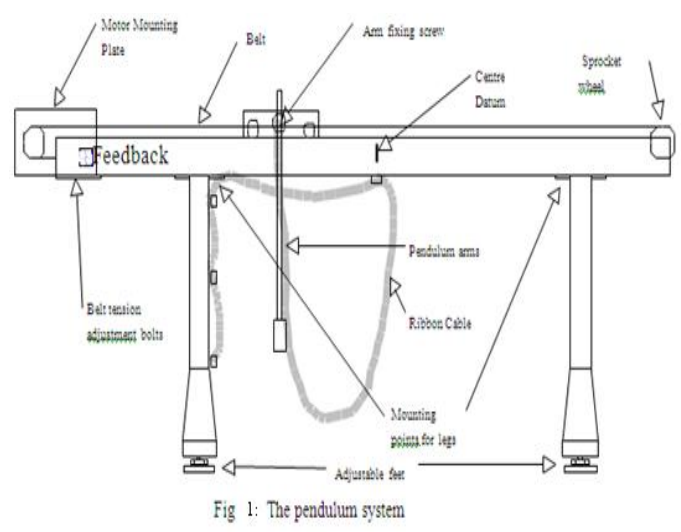

The system comprises of a horizontal plate connected to two wheels through a connecting rod. The wheels are independent of each other and are placed in the centre of the rail. The platform thus can move on a horizontal surface and is able to rotate about the axis of wheels. There are two masses on top of the system that can slide along the horizontal rail, the masses being on both sides of the rail. The system is shown in fig (1)

\section{MATHEMATICAL MODEL OF THE PLANT}

Defining the angle of the rod from the vertical (reference) line as $\theta$, displacement of the cart as $\mathrm{x}$, assuming the force applied to the system be $F$, centre of gravity of the pendulum rod is at its geometric centre and $\mathrm{l}$ be the half length of the pendulum rod, the physical model of the system is shown in fig (2). 
The Lagrangian of the entire system is given as,

$\left.\mathrm{L}=\frac{1}{2}\left(\mathrm{~m} \dot{\mathrm{x}} 2+2 \mathrm{ml} \dot{\mathrm{x}} \dot{\hat{\theta}} \cos \square+\mathrm{ml}^{2} \dot{\theta} 2+\mathrm{M} \dot{\mathrm{x}} 2\right)+\frac{1}{2} \mathrm{I} \dot{\theta} 2\right]-\mathrm{mgl} \cos \square$

The Euler-Lagrange's equation for the system is :

$$
\begin{aligned}
& \frac{\mathrm{d}}{\mathrm{dt}}\left(\frac{\delta \mathrm{L}}{\delta \dot{\mathrm{x}}}\right)-\frac{\delta \mathrm{L}}{\delta \mathrm{x}}+\mathrm{b} \dot{\mathrm{x}}=\mathrm{F} \\
& \frac{\mathrm{d}}{\mathrm{dt}}\left(\frac{\delta \mathrm{L}}{\delta \dot{\theta}}\right)-\frac{\delta \mathrm{L}}{\delta \theta}+\mathrm{d} \dot{\theta}=0
\end{aligned}
$$

The dynamics of the entire system using above equation is

$$
\begin{aligned}
& \left(I+\mathrm{ml}^{2}\right) \ddot{\theta}+\mathrm{ml} \cos \theta \ddot{\mathrm{x}}-\mathrm{mgl} \sin \theta+\mathrm{d} \dot{\theta}=0 \ldots \\
& (\mathrm{M}+\mathrm{m}) \ddot{\mathrm{x}}+\mathrm{ml} \cos \theta \ddot{\theta}-\mathrm{ml} \sin \theta \dot{\theta}^{2}+\mathrm{b} \dot{\mathrm{x}}=\mathrm{F}
\end{aligned}
$$

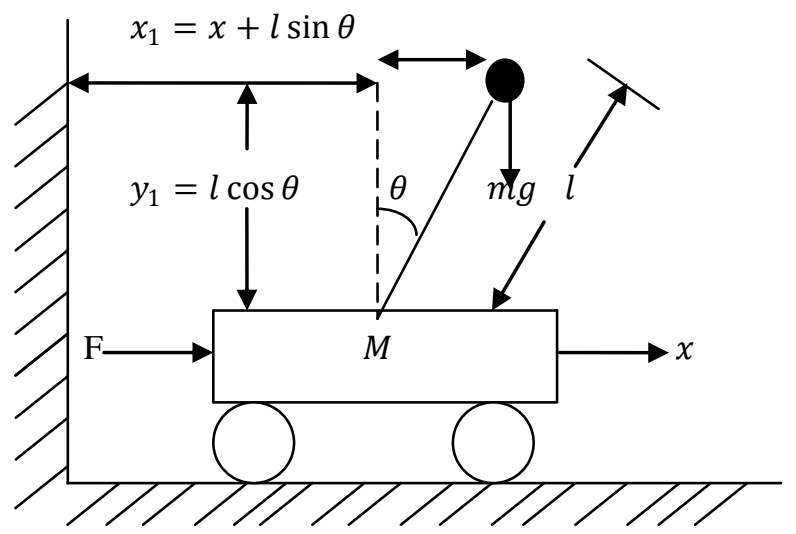

Fig 2 : The Inverted Pendulum System

In order to derive the linear differential equation model, the non linear differential equation obtained need to be linearized. For small angle deviation around the upright equilibrium (fig.2) point, assumption made

$\sin \theta=\theta, \cos \theta=1, \dot{\theta}^{2}=0$

Using above relation, equation (3) and (4) is derived.

$\mathrm{r} \ddot{\theta}+\mathrm{q} \ddot{\mathrm{x}}-\mathrm{k} \theta+\mathrm{d} \dot{\theta}=0$

$\ddot{p x}+q \ddot{\theta}+b \dot{x}=F$

)

Where, $(M+m)=p, m g l=k, m l=q, I+m^{2}=r$

Eq $(3 \& 4)$ is the linear differential equation model of the entire system.

Laplace transform model of the system is obtained substituting the parameter value (table 1),
$\frac{\theta(\mathrm{s})}{\mathrm{F}(\mathrm{s})}=\frac{-\mathrm{qs} \mathrm{s}^{2}}{\mathrm{rs}^{2}-\mathrm{k}+\mathrm{ds}}$

$$
\frac{\theta(s)}{F(s)}=\frac{-0.04283097 s^{2}}{0.1539 s^{4}+0.01265 s^{3}-0.6167 s^{2}-0.02099 s}
$$

$$
\frac{\theta(s)}{F(s)}=\frac{-0.2783 s^{2}}{s(s+2.026)(s-1.978)(s+0.03402)}
$$

and

$$
\begin{aligned}
\frac{X(s)}{F(s)}= & \frac{r s^{2}-k+d s}{\left(p r-q^{2}\right) s^{4}+(p d+b r) s^{3}+(b d-p k) s^{2}-k b s} \\
\frac{X(s)}{F(s)}= & \frac{0.106 \mathrm{~S}^{2}+0.005 \mathrm{~S}-0.4197}{0.1539 \mathrm{~s}^{4}+0.01265 \mathrm{~s}^{3}-0.6167 \mathrm{~S}^{2}-0.02099 \mathrm{~S}} \\
& \frac{\mathrm{X}(\mathrm{s})}{\mathrm{F}(\mathrm{s})}=\frac{0.68843(\mathrm{~s}+2.014)(\mathrm{s}-1.967)}{\mathrm{s}(\mathrm{s}+2.026)(\mathrm{s}-1.978)(\mathrm{s}+0.03402)}
\end{aligned}
$$

The system poles lies on R.H plane confirming the system to be unstable.

Table 1. Parameters of the system from feedback instrument .U.K.

\begin{tabular}{|l|l|l|}
\hline \multicolumn{1}{|c|}{ Parameter } & \multicolumn{1}{|c|}{ Value } & \multicolumn{1}{c|}{ unit } \\
\hline Cart mass $(M)$ & 1.206 & Kilo gram \\
\hline Mass of the pendulum $(m)$ & 0.2693 & Kilo gram \\
\hline $\begin{array}{l}\text { Half Length of } \\
\text { pendulum }(l)\end{array}$ & 0.1623 & $\mathrm{Ns} / \mathrm{m}$ \\
\hline $\begin{array}{l}\text { Coefficient of frictional } \\
\text { force }(b)\end{array}$ & 0.005 & $\mathrm{Mm} / \mathrm{rad}$ \\
\hline $\begin{array}{l}\text { Pendulum damping } \\
\text { coefficient(q) }\end{array}$ & 0.005 & $\mathrm{~kg} / \mathrm{m}^{2}$ \\
\hline $\begin{array}{l}\text { Moment of inertia of } \\
\text { pendulum }(I)\end{array}$ & 0.099 & $\mathrm{~m} / \mathrm{s}^{2}$ \\
\hline Gravitation force $(g)$ & 9.8 & \\
\hline
\end{tabular}

\section{PERFORMANCE INDICES}

The design of a control system is an attempt to meet a set of specifications which define the overall performance of the system in terms of certain measurable quantities. In the normal way, some specific parametric values of the system are assumed and the control system is designed accordingly to meet desired performance of the system.. Four most commonly mathematical functions are used as a performance index associated with error of a closed loop system. A performance index is a number which indicates goodness of system performance. The objective is to design an optimal system by proper choice of its parameters such that the specified performance index is optimum. A performance index must be a single positive number or zero, the latter being obtained if and only if the measure of the deviation becomes identically zero. 
The commonly used performance indices (PI) are:

- Integral of squared error (ISE),

$$
\mathrm{J}=\int_{0}^{\infty} e^{2}(t) d t
$$

- Integral of time multiplied squared error (ITSE),

$$
\mathrm{J}=\int_{0}^{\infty} t e^{2}(t) d t
$$

- Integral of absolute error (IAE),

$$
\mathrm{J}=\int_{0}^{\infty}|e(t)| d t
$$

- Integral of time multiplied absolute error (ITAE),

$$
\mathrm{J}=\int_{0}^{\infty} t|e(t)| d t
$$

Here the error is define as $e(t)=x(t)-y(t)$. The stable reference model has been taken for angle whose transfer function is

The transfer function of the system with angle as the output is

$$
\frac{\theta(\mathrm{s})}{\mathrm{F}(\mathrm{s})}=\frac{-0.04283097 \mathrm{~s}^{2}}{0.1539 \mathrm{~s}^{4}+0.01265 \mathrm{~s}^{3}-0.6167 \mathrm{~s}^{2}-0.02099 \mathrm{~s}}
$$

Table 2. The different performance indices with the angle of the pendulum as output.

\begin{tabular}{|c|c|}
\hline Performance Indexes & PID \\
\hline ISE & $\frac{-50.87 s^{2}-58.99 s-149.5}{s}$ \\
\hline ITSE & $\frac{-50.72 s^{2}-58.95 s-150.8}{s}$ \\
\hline IAE & $\frac{-50.66 s^{2}-58.87 s-149.1}{s}$ \\
\hline ITAE & $\frac{-50.05 s^{2}-58.41 s-151.4}{s}$ \\
\hline
\end{tabular}

Table 3 The different performance indices with position of the cart as output

\begin{tabular}{|c|c|}
\hline Performance Indexes & PID \\
\hline ISE & $\frac{45.66 s^{2}-58.99 s-149.5}{s}$ \\
\hline ITSE & $\frac{42.78 s^{2}+174.6 s+22.42}{s}$ \\
\hline IAE & $\frac{44.56 s^{2}+187.9 s+22.4}{s}$ \\
\hline ITAE & $\frac{43.09 s^{2}-175.7 s-38.28}{s}$ \\
\hline
\end{tabular}

Transfer function of stable reference model with position of the cart is:

Reference Model

$$
\frac{X_{1}(s)}{F_{1}(s)}=\frac{s+2}{s^{4}+9 s^{3}+43 s^{2}+143 s+204}
$$

The transfer function of the system with position as the output is:

$$
\frac{X(s)}{F(s)}=\frac{0.106 s^{2}+0.005 s-0.4197}{0.1539 s^{4}+0.01265 s^{3}-0.6167 s^{2}-0.02099 s}
$$

\section{GENETIC ALGORITHM}

Genetic algorithms (GA) are search procedures inspired by the laws of natural selection and genetics. They can be viewed as a general-purpose optimization method and have been successfully applied to search, optimization and machine learning tasks. GA has the ability to solve difficult, multi dimensional problems with little problem-specific information and hence has been chosen as the optimization technique to solve various problems in control systems.

It has been shown that compared with other traditional heuristic optimization method, Genetic Algorithm is likely to be more computationally efficient. The controller parameters are usually determined by trial-and-error through simulation. In such case, the paradigm of GA appear to offer an effective way for automatically and efficiently searching for a set of control performance.

\section{SIMULATION \& RESULTS}

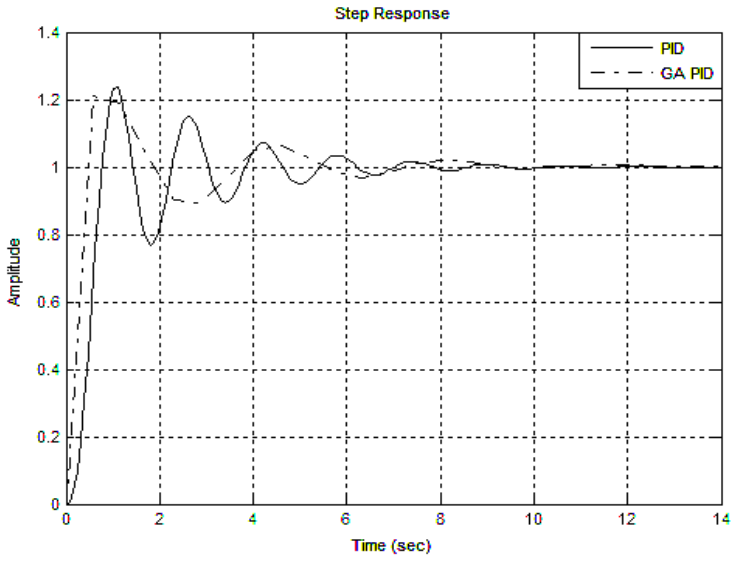

Fig. 3.ISE GA PID Controller of angle

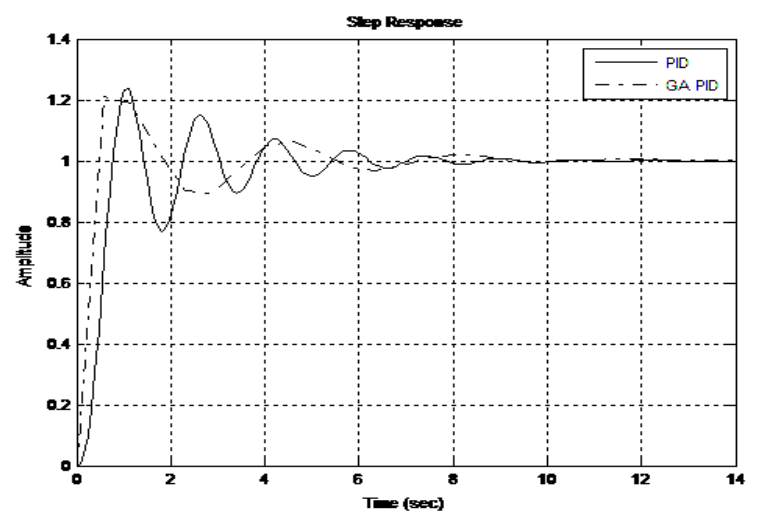

Fig. 4.ITSE GA PID Controller of angle 


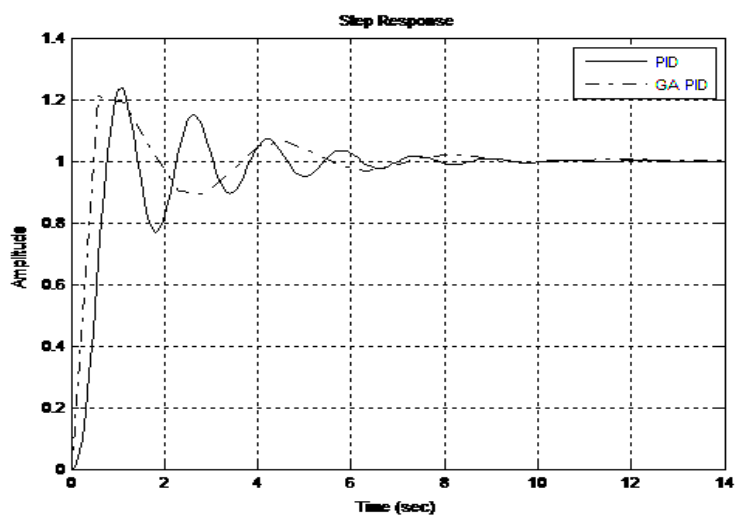

Fig. 5.IAE GA PID Controller of angle

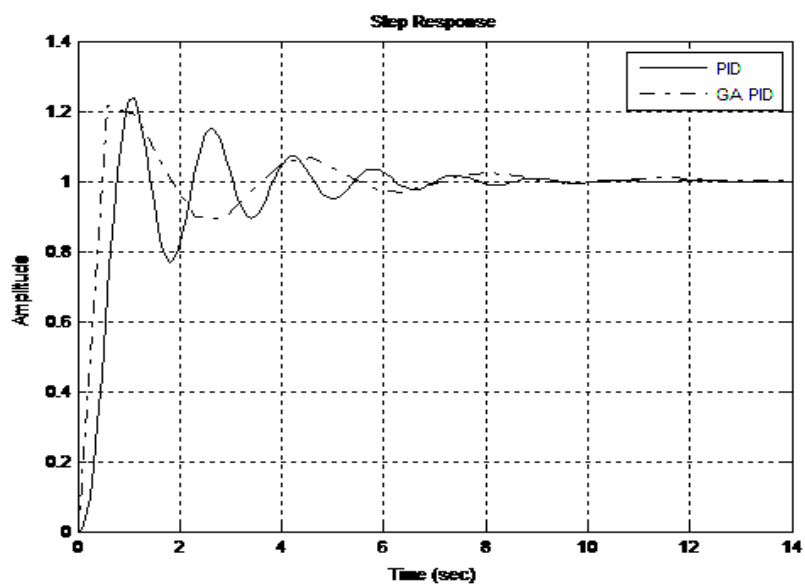

Fig. 6.ITAE GA PID Controller of angle

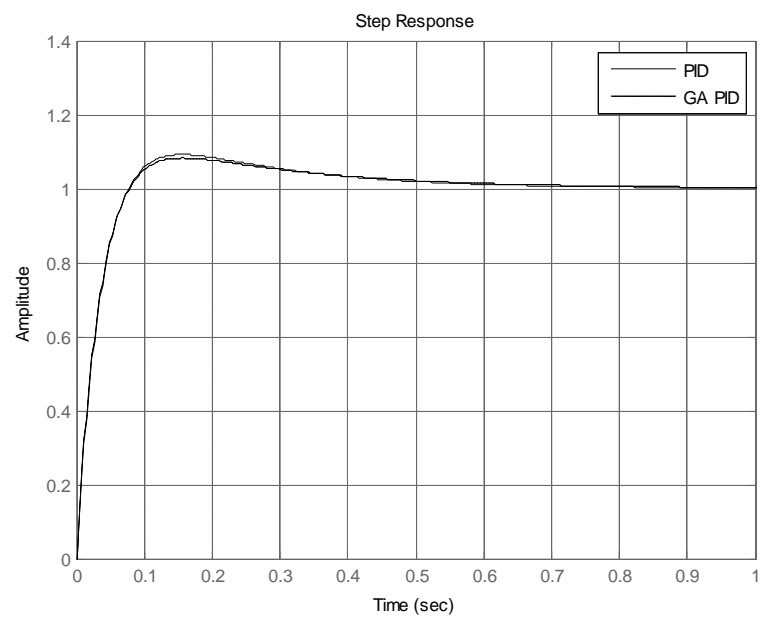

Fig. 7.ISE GA PID Controller of cart

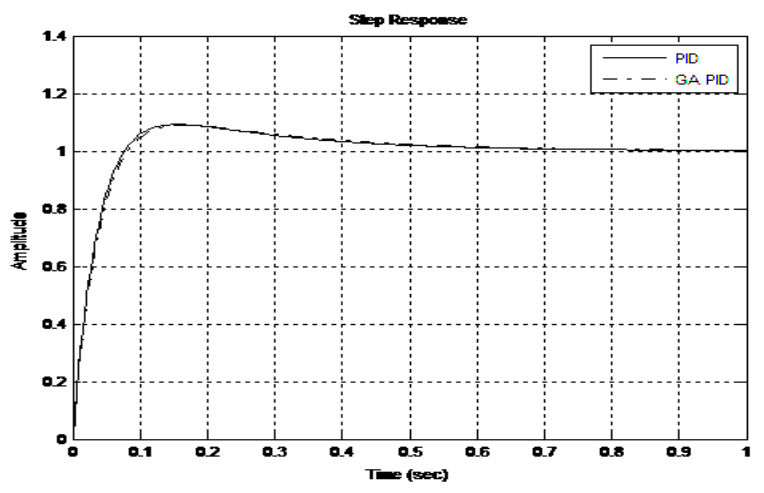

Fig. 8.ITSE GA PID Controller of cart

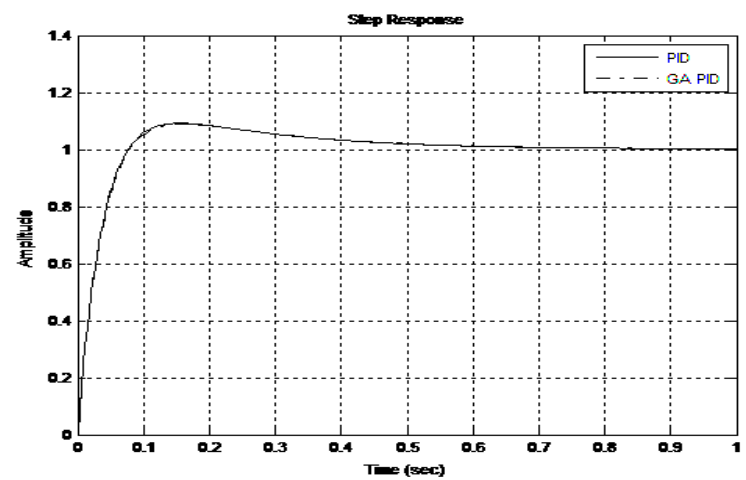

Fig. 9.IAE GA PID Controller of cart

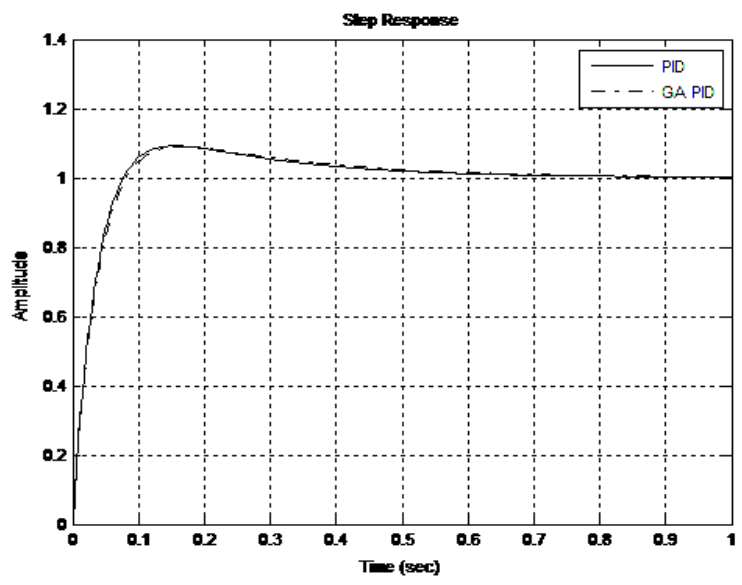

Fig. 10.ITAE GA PID Controller of cart

\section{CONCLUSIONS}

Modeling of inverted pendulum shows that system is unstable with non-minimum phase zero. Results of applying PID controllers show that the system can be stabilized. while PID controller method is cumbersome because of selection of 
constants of controller, Constant of the controllers can be tuned by some Genetic Algorithm technique for better result. Results with GA tuned controller are better in respect of rise time and overshoot wgen the angle is measured. The choice of the reference model like that of our system yields comparatively better result. The use of Walsh function in equation $(1 \& 2)$ would help finding out the solution of non-linear differential equations thus helping towards the design of non-linear controller.

\section{REFERENCES}

[1] Elmer P. Dadias, Patrick S. Fererandez, and David J,"Genetic Algorithm on Line Controller For The Flexible Inverted Pendulum Problem", Journal Of Advanced Computational Intelligence and Intelligent Informatics

[2] ] R. Murillo Garcia1, F. Wornle1, B. G. Stewart1 and D. K. Harrison1, "Real-Time Remote Network Control of an Inverted Pendulum using ST-RTL", 32nd ASEE/IEEE Frontiers in Education Conference November 6 - 9, 2002, Boston, MA.

[3] DONGIL CHOI and Jun-Ho Oh "Human-friendly Motion Control of a Wheeled Inverted Pendulum by Reduced-order Disturbance Observer" 2008 IEEE International Conference on Robotics and Automation Pasadena, CA, USA, May 19-23, 2008.

[4] W. Wang, "Adaptive fuzzy sliding mode control for inverted pendulum," in Proceedings of the Second Symposium International Computer Science and Computational Technology(ISCSCT '09) uangshan, P. R. China, 26-28, Dec. pp. 231-234, 2009.

[5] Berenji HR. A reinforcement learning-based architecture for fuzzy logic control. International Journal of Approximate Reasoning 1992;6(1):267-92.

[6] I. H. Zadeh and S. Mobayen, " PSO-based controller for balancing rotary inverted pendulum, " J. AppliedSci., vol. 16, pp. 2907-2912 2008.

[7] I. H. Zadeh and S. Mobayen, " PSO-based controller for balancing rotary inverted pendulum, " J. AppliedSci., vol. 16, pp. 2907-2912 2008.

[8] Mohd Rahairi Rani,Hazlina Selamat,Hairi Zamzuri,"Multi Objective Optimization For PID Controller Tuning Using The Global Ranking Genetic Algorithm",International Journal Of Innovative Computing, Information and Control, VOL-8, Number 1(A),January-2012

[9] Ohsumi A, Izumikawa T. Nonlinear control of swing-up and stabilization of an inverted pendulum. Proceedings of the 34th Conference on Decision and Control, 1995. p. 3873-80.

[10] Eiben, A.E., Hinterding, R. and Michalewicz, Z. Parameter Control in Evolutionary Algorithms. IEEE Transactions on Evolutionary Computation, 3, 2 (1999), 124-141.

[11] Kumar,P, Mehrotra, O.N, Mahto, J, Mukherjee, Rabi Ranjan,"Modelling and Controller Design of Inverted Pendulum", National Conference on Communication, Measurement and Control, Vol-I, 14th August, 2012,in press.

[12]Kumar,P, Mehrotra, O.N, Mahto, J, Mukherjee, Rabi Ranjan,"Stabilization of Inverted Pendulum using LQR",
National Conference on Communication, Measurement and Control, Vol-I, 14th August, 2012 in press.

[13] Behra Laxmidhar \& Kar Indrani; Intelligent Systems and Control Principals and Applications; Oxford University Press [14]Ogata, K.; System Dynamics, 4th Edition Englewood Cliffs, NJ: Prentice-Hall, 2003.

[15]Goldberg, D.E. Genetic Algorithms in search, optimization, and machine learning. Reading, Mass. : Addison-Wesley, 1989. [16] feedback instrument,U.K

\section{BIOGRAPHIES:}

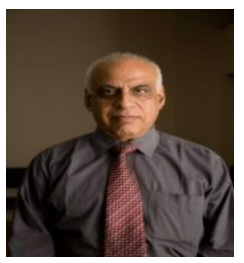

Mehrotra, a Gold Medalist at B.Sc. Engineering(B.U), M.E.(Hons)(U.O.R) and Ph.D. (R.U) all in Electrical Engineering, has the industrial exposure at SAIL as Testing \& Commissioning Engineer. Served Department of Science \& Technology, Govt. of Bihar \& Govt. of Jharkhand for 35 years and retired as Professor in Electrical Engineering. Served as coordinator of various projects sanctioned through MHRD and AICTE, including TEQIP, a World Bank Project. His research interests include control and utilization of renewable energies, power quality and power system.

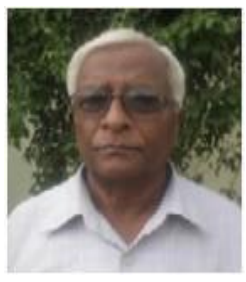

Jagdeo Mahto was born in Madhubani, Bihar, India, in 1943. He obtained the B.Sc (Engg) degree in Electrical Engineering from Bhagalpur University in 1964, M.Tech. in Control System from IIT Kharagpur, India in 1970 and Ph.D in Control System in 1984 from IIT Delhi, India. He served MIT Muzaffarpur from 1964 to 1971 in the capacity of Lecturer and Assistant Professor. From 1971 to 1980 he served as Asst. Professor, from 1980 to 1985 as Associate Professor and from 1985 to 1988 as Professor in the Department of Electrical Engineering at BIT Sindri, India. He taught at Bright Star University, Brega (Libya) from 1988 to 1989. From 1989 to 2003 he was again at BIT Sindri. From 2004 till date he is Professor at Asansol Engineering College, India.

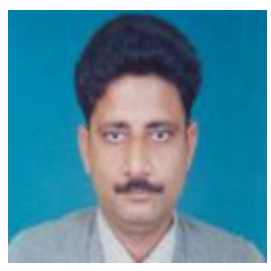

Pankaj Kumar was born in Muzaffarpur, India, in 1970 and received the B.Sc and M.Sc. degree in Electronics Honours and Electronic Science respectively from Magadh University and Gauhati University Assam. He received M.Sc Engineering in Control System Engineering from Patna University in 2004. He began his career as Lecturer in Bihar University Muzaffarpur. Currently he is an Assistant Professor in the Department of Electrical Engineering, Asansol Engineering College, Asansol, India. 